\title{
ОТЛИЧИТЕЛЬНЫЕ ЧЕРТЫ ПРОЦЕССА ИНВЕСТИРОВАНИЯ В УСЛОВИЯХ ИНФОРМАЦИОННОЙ ТРАНСФОРМАЦИИ РОССИЙСКОЙ ЭКОНОМИКИ
}

\author{
(c) 2020 Коновалова М.E. \\ доктор экономических наук, профессор \\ Самарский государственный экономический университет, Россия, Самара \\ mkonoval@mail.ru \\ (C) 2020 Кузьмина О.Ю. \\ кандидат экономических наук, доцент \\ Самарский государственный экономический университет, Россия, Самара \\ pisakina83@yandex.ru \\ (C) 2020 Ляченков Ю.Н. \\ соискатель кафедры экономической теории \\ Самарский государственный экономический университет, Россия, Самара
}

В статье рассмотрены основные особенности инвестирования в условиях становления и развития шестого технологического уклада, а именно одной из его стадий - цифровизации. Актуальность исследования определяется тем, что использование современных цифровых платформ расширяет инвестиционные возможности хозяйствующих субъектов, усиливает их мотивацию к осуществлению инвестиционной деятельности. Цель исследования состоит в выявлении специфических особенностей процесса инвестирования в условиях развития информационной экономики с применением современных цифровых инструментов. В процессе исследования использовались статистические, сравнительные и логические методы. В рамках исследования осуществлен свот-анализ сильных и слабых сторон, а также возможностей и угроз внедрения цифровых технологий в российской экономике. Выводы, полученные в ходе исследования, доказывают тот факт, что развитие информационных и цифровых технологий снижает роль посредников в механизме инвестирования, что сокращает трансационные и трансформационные издержки.

Ключевые слова: информационная экономика, цифровизация, инвестиционный процесс, финансовые технологии, информационные технологии, краудфандинг, «сквозные» технологии, инвестиционное поведение.

\section{Основные положения:}

- цифровизации представляет собой один из этапов становления и развития информационного общества и шестого технологического уклада, ядром которого являются современные цифровые технологии, облачные и цифровые сервисы, искусственный интеллект, когнитивные технологии;

- особое значение цифровизация приобретает в процессе осуществления инвестиционной деятельности, поскольку внедряемые новые инструменты инвестирования, такие как краудфандинг, краудлендинг, ICO обусловливают трансформацию традиционного поведения хозяйствующих субъектов, усиливая их мотивацию к инвестированию за счет снижения трансакционных издержек;

- наряду с положительным влиянием, ока- зываемым цифровыми технологиями на расширение инвестиционных возможностей, существуют и определенные ограничении, связанные с ростом инфраструктурных, экономических и социальных рисков.

\section{Введение}

Одной из стадий развития шестого технологического уклада является цифровизации. С точки теории долгосрочного техникотехнологического развития, предложенной С.Глазьевым, технологический уклад представляет собой макроэкономический воспроизводящий контур, который охватывает ключевые стадии процесса воспроизводства, в том числе производство и потребление. При этом ядро технологического уклада не всегда является отраслевым, его могут образовывать определенные виды экономической деятельно- 
сти, технологии, например, информационнокоммуникационные [1]. Совокупность же базовых принципов ведения хозяйства и поведения экономических агентов предстает в виде технико-технологической парадигмы. В ее основе лежит субъективное восприятие акторами происходящих изменений. Немаловажное значение в развитии технико-технологической парадигмы играют институциональные нормы и правила, регулирующие поведение хозяйствующих субъектов. на современном этапе имеющая место технико-технологическая парадигма характеризуется распространением финансовых и институциональных нововведений, экспансия которых существенным образом расширяет инвестиционные возможности экономических агентов. Трансформация механизмы рыночного финансирования инвестиционных проектов обусловлена развитием информационных технологий, а также динамической конвергенцией институтов, регулирующих инвестиционный процесс.

Основной формой нововведений, затрагивающих инвестиционный процесс, является, внедрение цифровых платформ, которые представляют собой новые конструкции, программные подсистемы, интерфейсы и технологические процессы, имеющие как основной, так и периферийный характер [2]. Если говорить о видах существующих цифровых платформ, то следует заметить, что их три: во-первых, это технологическая конструкция, основная задача которой состоит в синтезе информационного массива и разнообразных программ для обработки данных, по сути, это программное обеспечение; во-вторых, бизнес модель, которая рассчитана на создание стоимости за счет ускорения обмена информации между потребителями инвестиционного продукта, что снижает трансформационные издержки на производство инновационного продукта; в-третьих, это маркетплейс, задача которого состоит в посредничестве и реализации пенообразующей функции на продукцию финансовых технологий.

Преимущество новых цифровых инструментов инвестирования, в качестве которых выступают платформы, состоят в их большей транспарентности, высокой скорости обработки информации, гибкости, что обеспечивает выход на рынок инновационного продукта, с более сложными характеристиками. Указанные выше особенности функционирования циф- ровых платформ детерминируют рост степени кастомизации экономических процессов, что видоизменят архитектонику не только производственных отраслей, но и социальной сферы. кроме того, использование цифровых платформ в качестве нового инструмента инвестирования трансформирует процесс создания добавленной стоимости, теперь она создается не только в процессе производства, как это имеет место в индустриальной эпохе, но и в сфере обращения, когда происходит продажа инновационной продукции, отличительной особенностью которой является ее высокотехнологичный характер. Обработка больших данных, связана с ростом потребления энергии, что говорит о продолжении цепочки создания новой стоимости в сфере обращения. Следует отметить, что данная гипотеза подтверждается выводами представителей энергетической теории стоимости, которая развивалась как отдельное направления затратной концепции.

Целью исследования является выявление ключевых особенностей осуществления инвестиционного процесса в условиях внедрения цифровых технологий в отечественной экономики, а также определение основных преимуществ инвестиционной деятельности с применением финансовых технологий.

\section{Методы}

В качестве основных методов в исследовании применялись метод сравнения, а также статистический, графический и табличные методы отражения фактического материала. Основой исследования послужила, полученная из официальных источников ЦБ РФ, а также крупнейших рейтинговых агентств.

\section{Результаты}

Если говорить о развитии цифровых технологий и их внедрении в инвестиционный процесс, то следует заметить, что эффект от такого инкорпорирования будет заметен только в случае тотального проникновения соответствующих технологий во все стадии воспроизводственного процесса, начиная с производства и заканчивая потреблением. Кроме того, данными технологиями должна пользоваться большая часть населения. Только в этом случае цифровизации станет отражением новой технико-технологической парадигмы [3], именно как нового руководящего принципа деятельности хозяйствующих субъектов, что детерминирует рост конкурентоспособности экономики в целом. Оценивая степень 
готовности российской экономики к внедрению и распространению цифровых технологий, следует отметить, что в текущий момент России достаточно динамично развивает и сам ІТсектор и производные его комплексы, причем изменения затрагивают практически все сферы, включая производство и обращение [4]. Если посмотреть на динамику роста интернет пользователем, то можно заметить ежегодный рост на $3 \%$, и достигает значения $80 \%$ от всего населения, при этом 60\% являются активными пользователями интернета. Растет численность населения, использующих мобильный интернет, их доля составляет $56,8 \%$. Увеличился доступ к широкополосному интернету, так, за период с 2013 по 2018 год показатель возрос в 1,5 раза. Что касается гендерной тенденции, то следует заметить, что наибольшей популярностью интернет технологии пользуются у представителей молодого поколения, среди участников опроса старшей возрастной группы (65 лет и больше), пользуются интернетом лишь каждый третий.

В целом, можно заметить, что Россия занимает достаточно устойчивую позицию в рейтинге стран, внедряющих цифровые технологии. Наибольшие показатели вовлеченности населения в информационную среду показывают Норвегия, Швеция, Дания, Люксембург, а также Южная Корея, Китай и др.

Если говорить об отраслевой структуре использования цифровых технологий, то на первом месте стоит индустрия развлечений, социальные сети (78\%), осуществление финансовых операция
(30,9\%). Такая незначительная доля лиц, использующих интернет в целях извлечения дохода, говорит о серьезном потенциале этой отрасли. Так, например, В Исландии и Норвегии 95\% субъектов пользуются интернет-банкингом.

Немаловажное значение развитие информационных технологий имеет для бизнес сообщества, так как они ускоряют производственные процессы, снижают трансационные и трансформационные издержки. Фирмы, в отличие от домашних хозяйств используют информационные технологии непосредственно в своей производственной деятельности (поиск контрагентов и деловой информации, ключевые финансовые операции и т.д.). Кроме того, в последние годы растет число пользователей «сквозных» цифровых технологий $[5,6]$. На сегодняшний день $22,6 \%$ фирм и организаций применяют данный вид технологий. В международных рейтинговых агентствах рассчитывается глобальный индекс цифровизации бизнеса, который характеризует скорость приспособления хозяйствующих субъектов к цифровой трансформации. По данному показателю Россия занимает предпоследнее место (31 из 33 стран), что говорит о высоких внутренних затратах на внедрение цифровых технологий и недостаточности бюджетных средств, выделяемых на развитие сквозных технологий (только 2,4\% ВВП или 81,4 млрд. руб.) Проведенный в исследовании SWOT анализ отражает все сильные и слабые стороны, а также возможности и угрозы внедрения цифровых технологий в нашей стране.

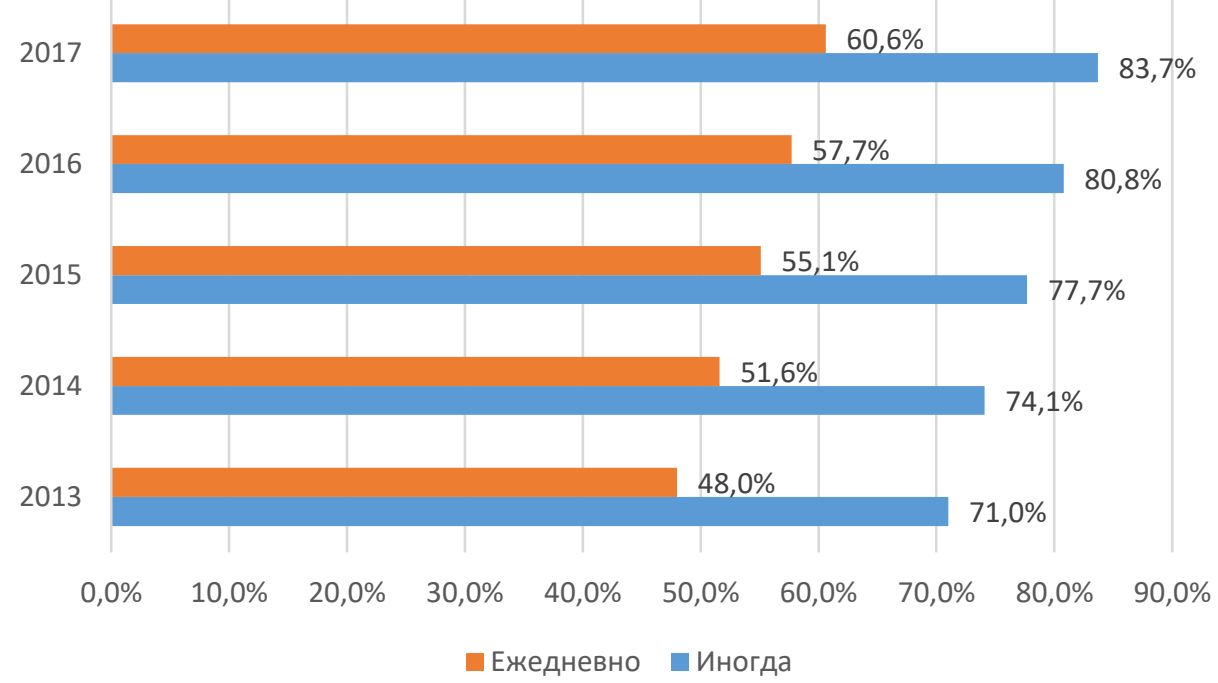

Puc. 1. Структура населения, использующего интернет 


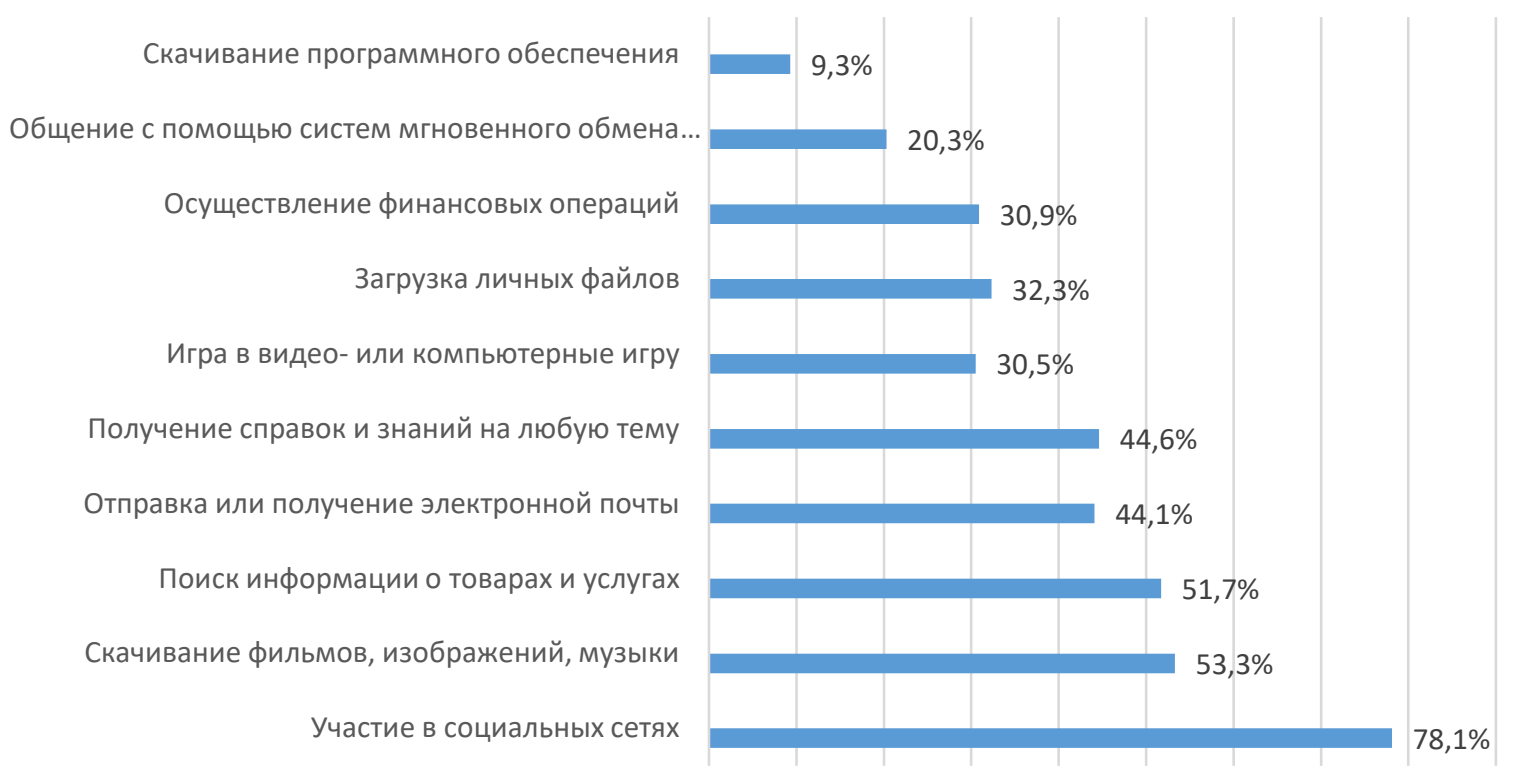

0,0\% 10,0\% 20,0\% 30,0\% 40,0\% 50,0\% 60,0\% 70,0\% 80,0\% 90,0\%

Рис. 2. Цели использования интернета населением в 2018 году (в процентах от численности населения в возрасте 15-74 лет, использующего интернет)

Таблица 1. SWOT-анализ формирования и внедрения «сквозных» цифровых технологий

\begin{tabular}{|c|c|}
\hline Сильные стороны & Слабые стороны \\
\hline $\begin{array}{l}\text { - использование виртуального пространства на всех } \\
\text { этапах производства продукта (услуги); } \\
\text { - улучшение качества предоставляемых услуг; } \\
\text { - снижение энергопотребления; } \\
\text { - увеличение кооперации между компаниями из } \\
\text { различных секторов экономики; } \\
\text { - ускорение транзакций и бизнес процессов; } \\
\text { - повышение транспарентности среды; } \\
\text { - оптимизация каналов коммуникации; } \\
\text { - снижение затрат на транзакцию финансовых и } \\
\text { операционных рисков; } \\
\text { - расширение географии спроса; } \\
\text { - кастомизация продуктов и услуг; } \\
\text { - снижение роли посредников; } \\
\text { - уменьшение числа ошибок, вызванных человече- } \\
\text { ским фактором }\end{array}$ & $\begin{array}{l}\text { - высокая стоимость решений и устройств; } \\
\text { - недостаточное количество качественного контен- } \\
\text { та; } \\
\text { - неравномерное распределения доступа населения } \\
\text { к интернету; } \\
\text { - проблемы трансграничной передачи данных; } \\
\text { - отсутствие стандартизации регулирования; } \\
\text { - нехватка квалифицированных кадров; } \\
\text { - отсутствие высокопроизводительных вычисли- } \\
\text { тельных мощностей; } \\
\text { - сложность интеграции с существующими систе- } \\
\text { мами, неготовность предприятий к использованию } \\
\text { технологий. }\end{array}$ \\
\hline Возможности & Угр \\
\hline $\begin{array}{l}\text { - увеличение производственной мощности; } \\
\text { - увеличение скорости доступа к интернету и его } \\
\text { трафика; } \\
\text { - увеличение объема рынка интеллектуальной } \\
\text { собственности; } \\
\text { - рост институционального доверия; } \\
\text { - рост М2М - решений; } \\
\text { - совершенствование пользовательского опыта; } \\
\text { - тенденция к портативности готовых продуктов }\end{array}$ & $\begin{array}{l}\text { - наличие проблемы безопасности хранения персо- } \\
\text { нальных данных (киберугрозы); } \\
\text { - отсутстве прозрачности процесса принятия } \\
\text { решений; } \\
\text { - сокращение рабочих в традиционных отраслях; } \\
\text { - рост конкуренции между компаниями, использу- } \\
\text { ющими IT- технологии; } \\
\text { - ухудшение управляемости процессами и эффек- } \\
\text { тивности в краткосрочной перспективе }\end{array}$ \\
\hline
\end{tabular}




\section{Обсуждение}

Необходимо заметить, что цифровые технологии влияют не только на процесс создания стоимости [7], но они существенным образом меняют поведение хозяйствующих субъектов. Если раньше основной мотивацией экономических агентов было потребление продукта, то в эпоху развития цифровизации и финансовых технологий - потребление сервисов. Развитие информационных технологий оказывает воздействие на спрос и предложения финансовых услуг, при этом резко возрастает вовлеченность в процесс инвестирования с помощью цифровых платформ домашних хозяйств. Особое значение быстрой экспансии новый финансовых услуг играет их транспарентность, доступность и простота применения, что существенным образом расширяет контингент пользователей, что в конечном итоге детерминирует улучшение их финансового благосостояния и способствует росту реального дохода [8]. Увеличение спроса на новые инструменты инвестирования обусловлено динамичностью их предложения, сектор IT предлагает все большее число разнообразных сервисов, цифровых платформ и иных решений, способствующих трансформации бизнес моделей. Следует отметить, что влияние информационно-коммуникационных технологий на развитие инвестиционного процесса помимо положительных моментов имеет и некоторые ограничения. Например, информационно-коммуникационные технологии порождают дополнительные риски, среди которых можно выделить инфраструктурные, экономические и социальные. Применяемые в финансовом сегменте информационные технологии могут порождать излишнюю волатильность финансового рынка, нестабильность неперсонифицированного институционального доверия как к конкретным финансовым продуктам, так и отдельным институтам [9]. Еще одно проявление инфраструктурного риска состоит в возможном ущербе от автоматического сбоя системы, несанкционированного доступа в нее (взлома). Существуют и экологические ограничения, связанные, как правило, с ростом энергозатрат и выбросов парниковых газов. Экономические риски связаны с несоответствием инвестиционных предпочтений и возможностей хозяйствующих субъектов, что при негативном сценарии ведет к росту закредитованности домашних хозяйств и бизнеса, следствием чего может иметь место рост долговой нагрузки. Помимо вышеобозначенных рисков, немаловажное значение имеют и социальные последствия, связанные с трансформацией рынка труда.

Внедрение цифровых технологий изменяет структуру рынка труда, трансформирует традиционные виды деятельности, живой труд заменяется информационными технологиями и искусственным интеллектом. Меняется и возрастная структура, представители старшего поколения, слабо владеющие информационными технологиями вытесняются более молодыми, поколением Z, рожденными уже в эпоху глобального интернета [10].

Представленные риски связаны между собой, что подчас усиливает их воздействие, как в процессе принятия инвестиционного решения, так и непосредственного при его реализации.

\section{Заключение}

Проведенное исследование позволило вывить ключевые особенности инвестиционного процесса в условиях развития информационной экономики и внедрения цифровых инструментов [11]. Во-первых, происходит принципиальная трансформация модели поведения хозяйствующих субъектов, традиционная сберегательная мотивация уступает место инвестиционной. Во-вторых, расширяется контингент участников, вовлеченных в инвестиционный процесс, все большее значение приобретает сектор домашних хозяйств как полноценный участник инвестиционного процесса. В-третьих, существенным ограничением экспансии новых финансовых инструментов в инвестиционном промессе выступает недостаточное развитие и внедрение IT технологий во все стадии воспроизводственного процесса, что обусловлено высокими трансформационными издержками, и низким уровнем финансирования «сквозных» трехногий. Следует заметить, что в развитии информационных технологий в наибольшей степени заинтересованы крупные корпорации, а также кредитные организации, венчурные фонды, акселераторы и инкубаторы, а также их клиенты (фирмы и домашние хозяйства), которые могут выступать в качестве инвесторов, что обусловливает расширение инвестиционных возможностей хозяйствующих субъектов. Традиционные способы и инструменты постепенно утрачивают свое значение, уступая новым цифровым сервисам, платформам и другим механизмам осуществления инвестиционной деятельности 
[12]. Привлекательность использования новых инструментов инвестирования связана, во-первых, с возможностью реализации бизнес идей и инвестиционных проектов в сети интернет с применением цифровых платформ; во-вторых, с незначительными финансовыми вложениями и затратами в основные производственные фонды, что уменьшает трансформационные издержки предприятий и снижает стоимость гото- вой продукции.

Основные выводы и результаты, полученные в ходе исследования могут быть использованы при разработке программы развития цифровизации экономики на региональном уровне, а также применяться в практике отдельных фирм и организаций, стремящихся использовать современные цифровые технологии в процессе инвестирования.

\section{Библиографический список}

1. Глазьев С. Какая модернизация нужна России? // Экономист. - 2010. - № 8.- С. 7.

2. Сухарев О. Институциональная экономика/ - М.: Экономика, 2008.- С. 257

3. Dosi J.Sourses,. Procedures and microeconomic effects of innovation // Journal of economic literature.-1988.XXVI - P.1124-1128

4. Яковец Ю.В. Формирование постиндустриальной парадигмы: истоки и перспективы // Вопросы философии. - 1997. - № 1. С.5.

5. Маркарян К. Н. Закон сохранения капитала / - М.: ЭКСМО. 2004. С. 56-58.

6. Полещук Н.Г. Энерговооруженность и производительность труда / - М.: Прогресс. 1973.- С. 234-235

7. Вальтух К. К. Информационная теория стоимости и законы неравновесной экономики /- М.: Дрофа, 2001. С. 78-79.

8. Стратегия развития информационного общества в Российской Федерации на 2017-230 гг. Утвержденная Указом Президента РФ от 9.мая 2017 № 203/URL: http:// kremlin.ru/acts/bank/41919.

9. The Digital Economy and society index (DESI) / European Commission- URL: https://ec.europa.eu/digital-singlemarket/en/desi

10. Цифровые технологии в российских компаниях: результаты исследования (январь 2019 г.) / KPMG -URL: https://home.kpmg/ru/ru/home/insights/2019/01/digital-technologies-in-russian-companies-survey.html (

11. Mikhailov A.M., Kopylova A. A. Relationship Between the Economy Digitalization and the "Knowledge" Production Factor. Lecture Notes in Networks and Systems (см. в книгах). 2020.T. 84. с. 27-38.

12. Коновалова М.Е., Михайлов А. М., Кузьмина О.Ю. Прогнозирование развития фондовых рынков в условиях становления цифровой экономики //Вестник Самарского государственного экономического университета. 2018.№ 11 (169). С. 13-19. 